\title{
Effects of Training of Eye Fixation Skills on the Reading Fluency of Children with Oculomotor Dysfunction
}

\author{
Muhammad Nazir* \\ Tanzila Nabeel $^{* *}$
}

\begin{abstract}
The study was carried out to determine the effect of training of eye fixation skills on the reading fluency of Children with Oculomotor Dysfunction. Pretest-Posttest Control Group Design was used in this experimental study. All the school going children having Oculomotor Dysfunction and poor reading skills between the ages5-14 years at primary level were population of this study. King Devick Pro Reading test was run on the children with poor reading abilities to diagnose the Children with Oculomotor Dysfunction. Children having percentile rank below 15 or below average accuracy on King Devick Pro Reading test were diagnosed as Children with Oculomotor Dysfunction. 20 Children with Oculomotor Dysfunction were selected from a pool of 50 Children with Oculomotor Dysfunction using random sampling technique. Two cohorts (experimental and control) having 10 Children with Oculomotor Dysfunction each, were used in the study. The level of Visual Fixation Skills of the children of both of the groups was analyzed sing Nova Southeastern University College of Optometry Oculomotor Test. The subjects of experimental group underwent training of manual and computer animated visual fixation skills 50 minutes per day for 7 days a week for 6 weeks. Words Correct Per Minute Method was used to determine the reading fluency of both of the groups before and after the intervention from selected paragraphs of Punjab Textbook Board. Analysis of Covariance was employed to make comparison between the level of reading fluency of Experimental Group and Control Group on
\end{abstract}

\footnotetext{
${ }^{*}$ Ph.D Scholar, Department of Special Education, Allama Iqbal Open University Islamabad, Email: muhammadnazir141@gmail.com

** Associate Professor, Department of Special Education, Allama Iqbal Open University Islamabad, Email: tanzilanabeel@gmail.com
} 
the basis of attained scores after the intervention. The results indicated that there was significant effect $(p=0.003)$ of the training of visual fixation skills on the reading fluency of Children with Oculomotor Dysfunction. A highly significant improvement $(p=0.001)$ in the eye fixation skills of the Children with Oculomotor Dysfunction was found through visual fixation exercises training.

Keywords: visual fixation skills, children with oculomotor dysfunction, reading fluency. 


\section{Introduction}

Reading is a multisensory activity which involves perceptual, intellectual and motor interaction with the reading material (Mangen, 2008). Good reading habit improves the speaking and writing skills. A person lacking good reading practice fails to be a good speaker and writer (Tyagi \& Misra, 2011). Poor reading ability develops weak reading comprehension skills and it frails academic achievement of a person in the later life (Justice, Mashburn \& Petscher, 2013). Alongwith language factors, there are some non-language factors which also effect reading ability of a person. These factors include nature of instruction, emergent literacy experiences, rapid naming, inspiration, attention, conceptual, perceptual, and skills of reasoning (Catts \& Kamhi, 1999). Different visual perceptual processing skills also affect the reading capacity of the children. Visual tracking skill is related to the eye movement and it plays key role in reading, copying, estimating a distance and road crossing (Farrell, 2006).

The term 'Oculomotor' is related to control of eye movement and it is one of simplest parts of visual system which can easily be trained. Oculomotor dysfunction affects the reading-ability and reading fluency of a person (Lane, 2005). Oculomotor dysfunction affects a person in terms of trouble reading, ocular discomfort, eye fatigue, rubbing eyes while reading, evading reading, sleeping during the reading, use of finger while reading (Petrosyan, 2013). Oculomotor dysfunction is one of the major causes of poor reading ability among children. Eye fixation loss, or extra eye fixation and saccades in search tasks are the indications of oculomotor dysfunction (Scheiman \& Rouse, 2006). The speed of reading of a child is reduced by the slow eye movements (Lederman, 2012). Learning to read is a complicated phenomenon which involves visual processing and oculomotor functions. In the process of learning to read, the eyes should have ability to concentrate (form saccades) and make focus (fixations) on letter-by-letter, word-by-word and line-by-line (Labor, 2010).Visual tracking exercises and eye teaming training can enhance the visual efficiency of a child and enable him/her to effectively focus (make visual fixation)on a line of print while reading (Sekznick, 2012). Visual tracking involves three types of visual skills i.e. fixation, saccade and pursuit. These skills are core of our visual system (ShawMcMinn, 2014). Oculomotor based training improves the reading as well as control over the eye movements and overall reading capacity (Thiagarajan, Ciuffreda, Capo-Aponte, Ludlam \& Kapoor, 2014). 
Fixation eye movement is very important for reading and focusing the gaze on subjects. The Fischer (2015) found that successful training of visual fixation and saccadic skills improve reading ability of dyslexic children. Rosengarth et al. (2013) also noted positive effect of oculomotor training on fixation stability, visual acuity and reading speed of people with age-related macular degeneration. The training of visual fixation skills may help to improve the involuntary eye movements and thus help to increase the level of reading fluency of the Children with Oculomotor Dysfunction (OMD). There was no study on the rehabilitation of fixation skills particularly in relation to reading fluency of Children with Oculomotor Dysfunction in Pakistan. Keeping in view the vital role of visual fixation skill's rehabilitation in improving the reading ability of children, present study aimed to investigate the "effect of training of Visual Fixation Skills on the Reading Fluency of Children with Oculomotor Dysfunction'. The research may help the School Education Authorities to monitor oculomotor skills and develop rehabilitation plan to improve eye movements of students and consequently enhance their reading fluency skills. Teachers can help the students to improve their reading ability by making adaptation in their teaching methodology involving numerous eye movement exercises by remediating the visual fixation skills of children.

\section{Objectives of the Study}

Following were the study objectives:

1. To examine the effects of training visual fixation skills on the reading fluency of Children with Oculomotor Dysfunction.

2. To determine the effects of training through visual fixation exercises on the improvement of visual fixation skills of Children with Oculomotor Dysfunction.

\section{Research Hypotheses}

Researcher intended to investigate the following hypotheses:

$\mathrm{Ho}_{1}$ : There is no significant effect of training visual fixation skills on the reading fluency of Children with Oculomotor Dysfunction.

$\mathrm{Ho}_{2}$ : There is no significant effect of training through visual fixation exercises on the improvement of visual fixation skills of Children with Oculomotor Dysfunction. 


\section{Literature Review}

The defect or absence of purposeful, precise and voluntary movements of the eyes leads to cause the Oculomotor Dysfunction. The well-established and perfect oculomotor abilities are very important for playing sports, locating things in background, art work, copying information, writing, reading as well as numerous supplementary accomplishments people have to perform in this visual world. Oculomotor Dysfunction ordinary symptoms include consistent reading the same content again and again, weak reading comprehension and avoidance or reluctance for reading. A child with oculomotor dysfunction uses his/her fingers for reading most of the times. The use of finger for reading is developmentally normal behavior at a particular age, hence, this behavior is vanishes with the improvement of eye movements skills as the child gets older. But in case such behavior remains among the children, oculomotor dysfunction badly influences the academic performance and reading capacity (Johnson, 2016).

Basically visual tracking skills encompass three types of eye movement skills comprising of gaze fixation, saccade ability and pursuit skills. Knudson and Morrison (2002) explained that visual fixation skills denotes to the ability to carefully watch an object with visual attention and focus on it, on the other hand visual saccadic skill is referred to the fastvisual movement from one object to another. According to Koprinkova-Haristova, Mladinov \& Kasabov (2014), visual pursuit skill is the visual ability of a person to follow a moving object with his/her eyes.

Guzman-Martinez and Leung (2009) noted that visual training through informed-flicker enhanced the eye fixation ability as well as it also reduced the amplitude and quantity of visual saccades. Okumura, Laukkanen and Tamai (2008)found that oculomotor control and speed of reading among the adult readers was improved when provided the training of home based computerized visual saccade. On the other hand, Robert et al. (2014) offered numerous eye movement exercises such as visual fixation, visual saccades, visuospatial abilities in addition to eyehand coordination to respondents having developmental coordination disorder. The study had not yielded any positive influence of the eye movement exercises on horizontal visual pursuit skills; hence vertical visual pursuit ability was improved.

There is an effective association between the cognitive processes, speed of reading and the eye tracking ability. Brodney, Kehoe and Sinha (2010) carried out a study on grade- 1 to grade-4 elementary students. $\mathrm{He}$ conducted the survey with the help of Teacher Symptom Observation 
Survey (TSOS) test. He identified the students who had the capacity for the improvement of eye movement skills with vision therapy by using the Visagraph-II and Developmental Eye Movement (DEM) tests. The study was conducted to determine the impact of computerized vision therapy program on the oculomotor performance of students having vision problems. Students underwent computerized vision therapy for 20 weeks (twice a week) at the school. Posttest eye movement performance of the students was again evaluated with the help of DEM and Visagraph-II after the intervention. Students showed significant improvement in eye tracking abilities. The reading capacity of the children with oculomotor dysfunction was also improved by the use of vision therapy. The level of fixation duration was improved from 0.33 to 0.25 seconds per 100 fixations with the help of vision therapy of the children with oculomotor dysfunction.

The eye fixation skill and visual saccadic abilities are vitalelements of the normal eye tracking system. As compared to the poor readers, good readersexpress significant improvement in the eye movement skills on the basis of their visual fixation duration, length of visual saccades and number of visual regressions (Powers, Grisham \& Riles, 2008). The training of visual tracking skills through the vision therapy services or other visual exercises assists to improve the visual performance and reading. Solan, Larson, Shelley-Tremblay, Ficcara and Silverman (2001) noted that eye movement as well as comprehension therapy assists to enhance the reading abilities.

The training of eye movements has been linked with enhancement of reading speed; however the students are not usually trained in somatic performance of reading in the educational institutions. Wethe, Leong, Pang and Weil (2015) carried out a study to examine the impact of oculomotor training on the elementary students reading capacity. "Pretest and post-test training Academic Reading speed-related benchmarks were appraised for 09 children (Grade-1 to Grade-4) who underwent 6 weeks training in the school by the use of computer software (KingDevick Remediation)". A significant improvement was noted in the reading fluency of the students after the intervention $(p=0.008$, Wilcoxon signed-rank). The study indicated that training of visual tracking skills was very helpful in enhancing the reading capabilities of the learners.

The Fischer (2015) found that successful training of visual fixation and saccadic skills improve reading ability of dyslexic children. He stated that training of visual fixation and saccade can help to control the deficits in saccadic ability of an individual. The success rate of the visual tracking training was found in $85 \%$ such cases. A training program of 
dynamic task testing vision was utilized to improve reflexive saccade system, fixation system in addition to antisaccade system. The intervention was given to each dyslexic child individually keeping in view their eye movement results during antisaccade task with gap conditions and prosaccade task with overlap conditions. A distinctive gadget namely Fix Train was designed for the visual tracking training to be provided at home. The results indicated significant improvement in the reading capacity of the dyslexic children through the training of eye fixation and saccadic skills.

\section{Material and Method}

The study was quantitative in nature and carried out through true experimental design. The effects of independent variable (training of Visual Fixation Skills)on dependent variable (Reading Fluency of Children with Oculomotor Dysfunction) was demonstrated after the intervention using Randomized, Pretest-Posttest Control Group Design (Martella, Nelson, Morgan \& Marchand-Martella, 2013).The research design has been represented schematically as under:

Random Assignment

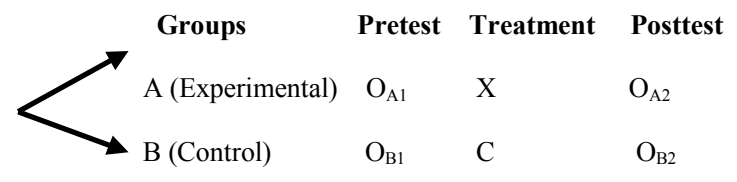

Where

$\mathrm{O}_{\mathrm{A} 1}$ Pre-Intervention evaluation of reading fluency of Group A

$\mathrm{O}_{\mathrm{A} 2}$ Post-Intervention evaluation of reading fluency of Group A

$\mathrm{X}$ Intervention (training of Visual Fixation Skills) provided to Group A

$\mathrm{O}_{\mathrm{B} 1}$ Pre-Intervention evaluation of reading fluency of Group B

$\mathrm{O}_{\mathrm{B} 2}$ Post-Intervention evaluation of reading fluency of Group B

C Control Condition (No Intervention)

There is an association between the improvement of reading fluency and the effectiveness of the visual fixation skills by the training through manual and computer animated visual fixation exercises. Therefore, the effect of training through visual fixation exercises on the improvement of visual fixation skills was also determined in the current study. Children with Oculomotor Dysfunction (OMD Children) were divided into two groups (experimental group and control group). The intervention in terms of manual and computer animated eye fixation exercises was provided to 
the experimental group. No any intervention was provided to the control group. The level of reading fluency and visual fixation skills of experimental and control group were evaluated before and after the intervention to ascertain the difference between pretest and posttest scores.

\section{Participants}

All the school going children having Oculomotor Dysfunction and poor reading skills between the ages5-14 years at primary level were population of this study. The potential population of the study was located by the researcher by visiting 12 primary schools of district Toba Tek Singh. Researcher identified the poor readers $(\mathrm{N}=206)$ with the help of their teachers. In order to confirm the inclusion of OMD Children on the basis of their poor tracking abilities, researcher measured the level of Visual Fixation, Visual Saccade and Visual Pursuit abilities before the intervention. The children with poor visual oculomotor skills (Fixation, Saccade and Pursuit) $(\mathrm{N}=50)$ were selected for the study. 20 OMD children were selected as a sample of the study on draw basis from the pool of 50 diagnosed OMD Children. Random assignment was made to divide the sample of 20 OMD children into two groups i.e. Experimental (Group A) and Control (Group B).

\section{Instruments}

Evaluation of Visual Tracking Skills (Fixation, Saccade and Pursuit Skills), Assessment of Reading Fluency and Diagnosis of OMD Children was made as follows:

\section{Diagnosis of Children with Oculomotor Dysfunction}

Children with Oculomotor Dysfunction were diagnosed with the help of King DevickPro Reading online test (KD Test) using a computer, on the children with poor reading abilities. Poor readers were required to read the alphanumeric values loudly with maximum speed without making errors on the Timed KD Test. The age of children and their total number of reading errors were entered in the online software of KD Test. The test results were compared with age-related normative values by the app automatically and showed the level of reading fluency of the participants in terms of percentile rank and accuracy (Mayo Clinic, 
2015). Children having below 15 percentile rank or with Below Average Accuracy on KD Test were diagnosed as Children with Oculomotor Dysfunction $(\mathrm{N}=53)$. The test-retest reliability of KD Test was established ( $\mathrm{r}=0.87)$ (Oberlander, Olson \& Weidauer, 2017).

Table 1

OMD Children score on KD Test regarding their Diagnosis

\begin{tabular}{cccccccc}
\hline \multirow{2}{*}{ Groups } & \multicolumn{3}{c}{ Percentile Rank } & \multicolumn{2}{c}{ Accuracy test } & \multicolumn{2}{c}{ Reading Error } \\
& Class & Mean & S.D & B.A & A & Mean & SD \\
\hline \multirow{4}{*}{ A } & 2 & 1.00 & .0 & 2 & 0 & 8.50 & .707 \\
& 3 & 6.67 & 4.93 & 3 & 0 & 6.00 & 4.58 \\
& 4 & 1.33 & .577 & 3 & 0 & 7.00 & 5.20 \\
& 5 & 1.00 & .0 & 2 & 0 & 9.50 & .707 \\
B & All & 2.80 & 3.55 & 10 & 0 & 7.50 & 3.57 \\
& 2 & 1.00 & .0 & 2 & 0 & 10.0 & 1.41 \\
& 3 & 5.00 & 1.00 & 3 & 0 & 6.00 & 1.73 \\
& 4 & 4.00 & 3.00 & 3 & 0 & 8.00 & 1.00 \\
& 5 & 4.50 & 2.12 & 2 & 0 & 6.00 & 1.41 \\
& All & 3.80 & 2.25 & 10 & 0 & 7.40 & 2.01 \\
\hline
\end{tabular}

B.A=Below Average, $A=$ Average, $S . D=$ Standard Deviation

\section{Assessment of Visual Fixation Skills}

The time duration of visual fixation during reading was measured in order to assess the level of Visual Fixation Skills. Children were required to read a paragraph for one minute, while the numbers of gaze fixations during reading were evaluated with the help of recorded videos. Total reading duration (in seconds) was divided by the number of visual fixations made to assess the level of Eye Fixation Skills of OMD Children before the intervention. The reliability of duration of Visual Fixation was established $(\mathrm{r}=0.89)$ on Visagraph II instrument (Borsting, Rouse, Shin, \& McClallen, 2007). The Visual Fixation Skills was measured before and after the intervention. 


\section{Measurement of Visual Saccadic and Pursuit Skills}

The level of Visual Saccadic and Pursuit Skills of OMD Children were measured using Nova Southeastern University College of Optometry (NSUCO) Oculomotor Test. NSUCO test was designed by Maples, O.D. in 1995. The test required minimum cooperation of the subjects and provided an economic and quick evaluation of visual tracking skills. The test was administered less than two minutes approximately. Two targets of pencils with coloured balls on the top were used (two targets for evaluation of visual saccadic skills and one target for the assessment of eye pursuit skills). The participants stood on their feet in front of the researcher a shoulder width-apart, arms hanging naturally on their sides at a distance not more than $40 \mathrm{~cm}$ and no less than Harmon Distance (Elbow to middle knuckle). No instruction was given to the subjects regarding the head and body movements. The movements head, body and eyes were observed in the test. The performance of subjects in four areas was graded in both the saccade and pursuit sections of the NSUCO test. The areas of 1) Ability, 2) Accuracy, 3) Degree of head movement, and 4) degree of body movement of the subjects were used to perform the activity. Thus total eight areas were evaluated; four areas for pursuit skills and four areas for saccadic ability (Maples, 1995). The intra-rater reliability of four areas of Saccades was established: "ability" showed 90\%, "accuracy" showed 62\%, "head movement" showed $86 \%$, and "body movement" showed $95 \%$. The four areas of Pursuits Skills showed intra-rater reliability: "ability" showed 95\%, "Accuracy" showed 90\%, "Head Movement" showed 76\%, and "Body Movement" showed 100\% (Maples, 1995). The level of Visual Saccadic and Pursuit Skills was measured before the intervention only.

\section{Measurement of the Level of Reading Fluency}

The level of reading fluency of OMD Children was measured using Word Correct Per Minute (WCPM) Method before and after the intervention. Five passages of Urdu subject were taken randomly from the Punjab Textbook Board (Grade-1 to Grade-5), in order to assess the level of reading fluency of OMD Children. WCPM Method helps the teacher to assess the rate of reading of their students (Hasbrouk \& Tindel, 2006). Total numbers of errors were subtracted from the total number of words read in one minute to calculate WPCM score (Shinn, 1989). Following errors were noted while reading of passage by the students: 1) omission, 2) substitution, 3) addition of word (which is not 
in the text), 4) mispronunciation, 5) self-corrected error by the student, 6) reading a word after a pause / break of 3-5 seconds, and 7) out of order reading. Reliability of all the five selected paragraphs from Punjab Textbook Board was determined to analyze its applicability for the research. The test-retest reliability coefficient (Cronbach Alpha) for the Grade-2 was $\mathrm{r}=0.98$, Grade- 3 was $\mathrm{r}=0.97$, Grade-4 was $\mathrm{r}=0.94$ and Grade-5 was $\mathrm{r}=0.98$.

\section{Intervention}

The experimental group underwent training in terms of Visual Fixation Exercises. An intervention of 42 sessions was given to experimental group, 50 minutes session per day, 7 sessions a week for 6 weeks. In order to improve the Visual Fixation Skills of OMD Children 05 manual and 02 computer animated visual fixation exercises were arranged each week. Effective training of visual fixation skills improves the reading ability (Fischer, 2015). Reliable sources were used to select the Eye Fixation Exercises (Special Education Resource Center, 2013; Heidi, 2011). OMD Children of experimental group were collected at a central location. A research assistant helped to conduct the Eye fixation exercises individually OMD Children. Following Eye Fixation Exercises were provided to the OMD Children:

Table 2

Classification of Eye Fixation Exercises

\begin{tabular}{cl}
\hline Type & Exercises \\
\hline I & Manual Eye Fixation Exercises \\
& Holding a small target \\
& Fruit loops fixation \\
& Stuff a straw \\
& Time limit sticker stare \\
& Lady bug noses \\
\hline II & Computer Animated Eye Fixation Exercises \\
& Shark Attack \\
& Oscillation Field \\
\hline
\end{tabular}




\section{Data Analysis}

Statistical analysis was made to analyze the effects of training of Eye Fixation Skills on Reading Fluency of OMD Children on the basis of scores of Experimental and Control group. Analysis of Variance (ANOVA) was employed to check the equivalence in age, reading fluency, eye fixation skills, visual pursuit skills and visual saccadic skills between the experimental and control group before the intervention. In order to compare the level of reading fluency of both the groups, Analysis of Covariance (ANCOVA) was employed. ANCOVA was also applied to examine the effectiveness of intervention (Eye Fixation Exercises) in improving the Eye Fixation Skills.

\section{Results}

20 Children with Oculomotor Dysfunction (10 experimental and 10 control group) were selected for the study. There was no any significant difference $(p>0.05)$ found in the age, reading fluency level and Eye Fixation Skills before the intervention.

\section{Effects of Gaze Fixation Skills training on Reading Fluency of OMD Children}

The Levene's test $F(1,18)=0.826, p>0.05$ verified the equality of variance among samples. The Shapiro-Wilk's test $(10)=0.194, p>0.05$ for Group A, (10) $=0.365, p>0.05$ for Group B showed that reading fluency data of both the groups was normally distributed. The ANCOVA values, $\mathrm{F}(1,16)=0.041, p>0.05$ verified the Homogeneity of Regression Slope and indicated that there was no interaction between the treatment and covariate. The visual inspection of Scatterplot showed that the scores of covariate and dependent variable were linearly related with each other. The above values showed that ANCOVA could be applied for the analysis of reading fluency of Children with Oculomotor Dysfunction. Partial eta-squared was explained using the values: 1) Partial Eta Squared Value 0.01=Small Size, Partial Eta Squared Value 0.06=Medium Size and Partial Eta Squared Value 0.14=Large Size (Hanna \& Dempster, 2012). 
Table 3

Comparison of the level of Reading Fluency between experimental and control group on post-test scores of WCPM Method after controlling pre-test scores

\begin{tabular}{ccccccccccccccc}
\hline Class & \multicolumn{4}{c}{ Group A } & \multicolumn{4}{c}{ Group B } & \multicolumn{4}{c}{ ANCOVA } \\
& $n$ & \multicolumn{2}{c}{ Pre-test } & \multicolumn{1}{c}{ Post-test } & $n$ & \multicolumn{2}{c}{ Pre-test } & Post-test & $F$ & $p$ & $\eta^{2}$ \\
& & $M$ & $S E$ & $M$ & $S E$ & & $M$ & $S E$ & $M$ & $S E$ & Value & Value \\
\hline 2 & 2 & 57.0 & 23.0 & 58.8 & .485 & 2 & 42.5 & 7.50 & 53.2 & .485 & 62.46 & .80 & .984 \\
3 & 3 & 50.3 & 4.98 & 73.7 & 4.16 & 3 & 65.3 & 11.1 & 60.3 & 4.16 & 4.49 & .124 & .600 \\
4 & 3 & 50.7 & 7.47 & 52.2 & 2.35 & 3 & 43.0 & 4.04 & 48.5 & 2.35 & 1.16 & .360 & .279 \\
5 & 2 & 60.0 & 21.0 & 74.0 & 1.57 & 2 & 74.5 & .500 & 69.6 & 1.57 & 3.48 & .313 & .377 \\
All & 10 & 53.7 & 5.36 & 64.7 & 1.61 & 10 & 55.9 & 5.54 & 56.8 & 1.61 & 11.74 & .003 & .409 \\
\hline
\end{tabular}

A=Experimental Group, $B=$ Control Group, $W C P M=$ Word Count Per Minute Method

A One-way between groups analysis of covariance was conducted to compare effectiveness of two different interventions designed to improve reading fluency of Children with Oculomotor Dysfunction. The independent variables were the type of treatments and the dependent variable was the level of reading fluency after the intervention. The preintervention score of the respondents was used as covariate in the analysis. The level of Reading Fluency was assessed before and after the treatment using WCPM Method.

After adjusting for pre-treatment, there were no significant differences in class $2, F(1,1)=62.46, p=0.80$, partial eta squared $=0.984$, class $3 F(1,3)=4.49, p=0.124$, partial eta squared $=0.600$, class $4, F$ $(1,3)=1.16, p=0.360$, partial eta squared $=0.279$, and class $5, F(1,1)=3.48$, $p=0.313$, partial eta squared $=0.377$. There was significant difference in combined scores of both groups, $F(1,17)=11.74, p=0.003$. Partial eta squared $=0.409$ showed that Effect size was large. The mean score of Group A $(M=64.7, S E=1.61)$ was greater than mean score of Group B $(M=56.8, S E=1.61)$. It showed that there was significant effect $(p<0.05)$ of Visual Fixation Skills training on the reading fluency of Children with Oculomotor Dysfunction. 


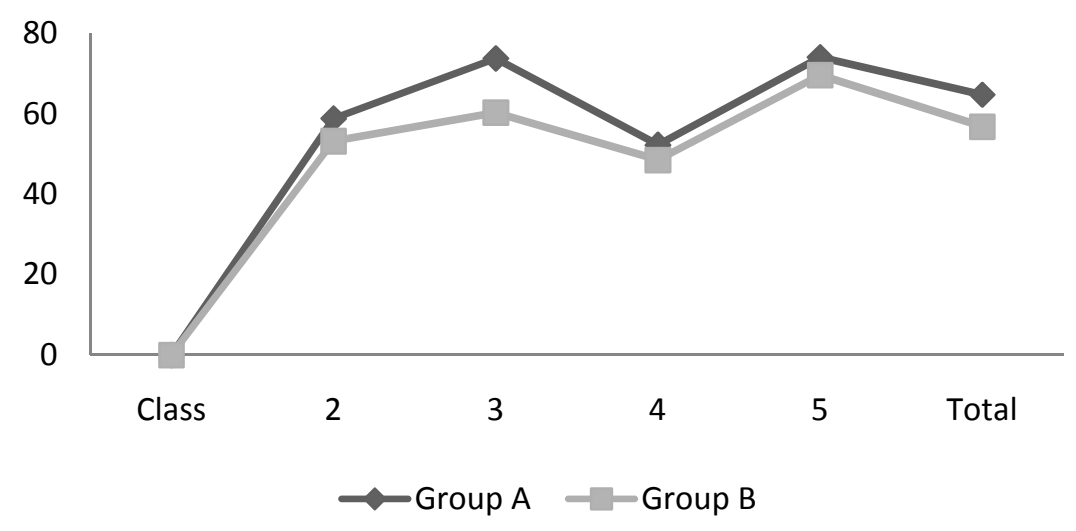

Figure 1: Representation of Reading Fluency between group A and B on post-test scores of WCPM Method after controlling pretest scores

\section{Effects of training of Eye Fixation Exercises on the Eye Fixation Skills of OMD Children}

The visual inspection of Scatterplot indicated that scores of covariate and dependent variable were linearly related with each other. The Shapiro-Wilk's test (10) $=0.971, p>0.05$ for Group A, (10) $=0.940, p>0.05$ for Group B revealed that data regarding the level of Eye Fixation Skills of both the groups was normally distributed. The equality of variance among the samples was verified by the Levene's test $F(1,18)=2.903$, $p>0.05$. The ANCOVA values, $\mathrm{F}(1,16)=0.605, p>0.05$ verified the Homogeneity of Regression Slope and indicated that there was no interaction between covariate and treatment. It was revealed from the above values that ANCOVA could be employed for the analysis of Eye Fixation Skills of OMD Children. 
Table 4

Comparison of the level of Visual Fixation Skills between two groups (A $\& B$ ) on the basis of treatment through visual fixation exercises

\begin{tabular}{|c|c|c|c|c|c|c|c|c|c|c|c|c|c|}
\hline \multirow{3}{*}{$\begin{array}{c}\text { Clas } \\
\mathrm{s}\end{array}$} & \multicolumn{5}{|c|}{ A } & \multicolumn{5}{|c|}{ B } & \multicolumn{3}{|c|}{ ANCOVA } \\
\hline & \multirow[t]{2}{*}{$N$} & \multicolumn{2}{|c|}{ Pre-test } & \multicolumn{2}{|c|}{ Post-test } & \multirow[t]{2}{*}{$n$} & \multicolumn{2}{|c|}{ Pre-test } & \multicolumn{2}{|c|}{ Post-test } & \multirow[t]{2}{*}{$F$ Value } & \multirow[t]{2}{*}{$p$ Value } & \multirow[t]{2}{*}{$\eta^{2}$} \\
\hline & & $M$ & $S E$ & $M$ & $S E$ & & $M$ & $S E$ & $M$ & $S E$ & & & \\
\hline 2 & 2 & .43 & .095 & .35 & .007 & 2 & .41 & .020 & .40 & .007 & 32.458 & .111 & .970 \\
\hline 3 & 3 & .48 & .015 & .41 & .011 & 3 & .49 & .018 & .46 & .011 & 13.439 & .035 & .818 \\
\hline 4 & 3 & .45 & .032 & .38 & .014 & 3 & .43 & .026 & .42 & .014 & 3.988 & .140 & .571 \\
\hline 5 & 2 & .48 & .065 & .41 & .021 & 2 & .47 & .070 & .45 & .021 & 1.774 & .410 & .640 \\
\hline All & 10 & .46 & .021 & .39 & .006 & 10 & .45 & .017 & .44 & .006 & 37.079 & .001 & .686 \\
\hline
\end{tabular}

A One-way between groups analysis of covariance was conducted to compare effectiveness of two different interventions designed to improve the level of Visual Fixation Skills of Children with Oculomotor Dysfunction of experimental group A and control group B. The independent variable was type of treatment (training through visual fixation exercises) and the dependent variable was the level of Visual Fixation Skills after the intervention. The pre-intervention score of the respondents was used as covariate in the analysis. The level of Visual Fixation Skills was assessed before and after the treatment by measuring the time duration of visual fixation in seconds.

After adjusting for pre-treatment, there were no significant differences between group A and B in class $2, F(1,1)=32.458, p=0.111$, partial eta squared $=0.970$, class $4, F(1,3)=3.988, p=0.140$, partial eta squared $=0.571$ and class $5, F(1,1)=1.774, p=0.410$, partial eta squared $=0.640$ but there was significant difference in class $3, F(1$, $3)=13.439, p=0.035$, partial eta squared was 0.818 . Effect size was large. There was significant difference $(p<0.05)$ between Group A and $B$ in class 3 . There was significant difference in combined scores of group A and group $\mathrm{B}, F(1,17)=37.079, p=0.001$. Partial eta squared $=0.686$ showed that Effect size was large. The mean score of Group A $(M=0.39, S E=0.006)$ was less than mean scores of Group B $(M=0.44, S E=0.006)$. It was concluded that Visual Fixation Skills of Group A were significantly improved $(p<0.05)$ 
as compared to group B after the intervention in terms of training of Visual Fixation Skills through visual fixation exercises.

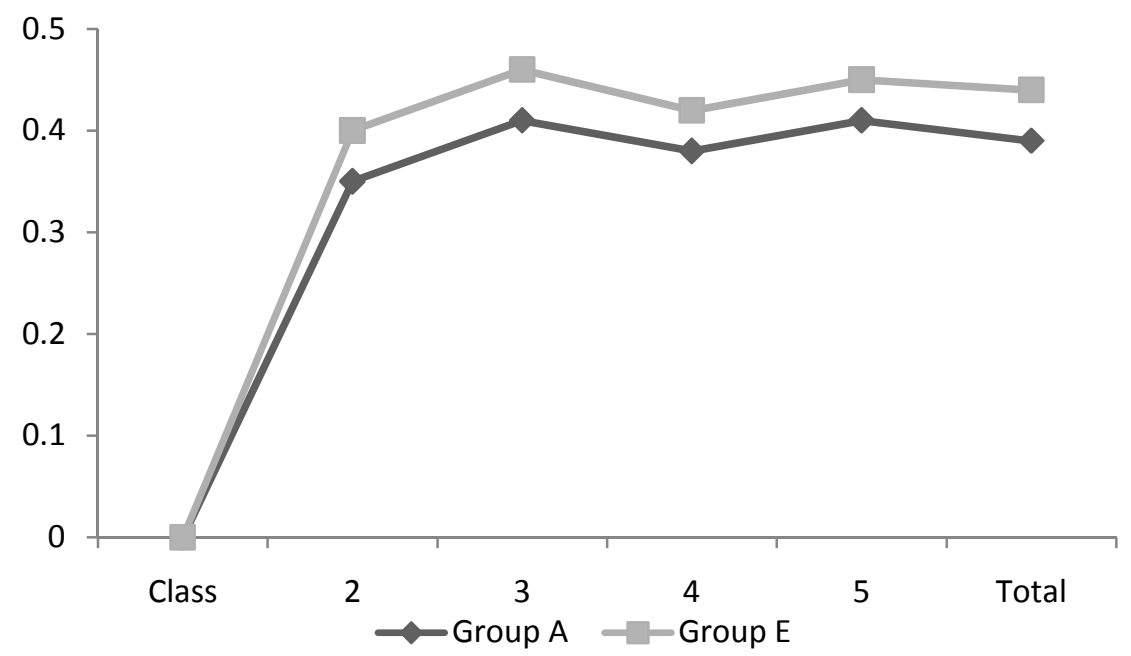

Figure 2: Representation of the level of Visual Fixation Skills between groups (A \&B) on post-test scores

\section{Discussion}

The study determined the effect of training of visual fixation skills on the reading fluency of OMD Children between experimental group A and control group B.No any significant difference was found in the level of reading fluency of both the groups before intervention. The research also examined the effect of intervention (training through visual fixation exercises) on the improvement of Visual Fixation Skills of OMD Children. Both the groups were statistically equal in the level of Visual Fixation Skills before intervention.

\section{Effect of Intervention on Reading Fluency of OMD Children}

The level of reading fluency of intervention group A was significantly better( 65 Words Per Minute) after the treatment in terms of training through Visual Fixation Exercises, than control group B (57 Words Per Minute). The mean score of Group A $(M=64.7, S E=1.61)$ was greater than mean score of Group $\mathrm{B}(M=56.8, S E=1.61)$. The data values $F(1,17)=11.74, p=0.003$. Partial eta squared $=0.409$ showed that Effect 
size was large. It indicated that there was significant effect $(p<0.05)$ of training of Visual Fixation Skills on the reading fluency of Children with Oculomotor Dysfunction .A study carried out by Fischer (2015) revealed that successful fixation and saccadic control training enhanced reading skills of dyslexic children. Similar study of Brodney, Kehoe and Sinha (2010) revealed significant effect of Vision Therapy using touch screen computers in the improvement of reading fluency of children having oculomtor problems.

\section{Effect of Intervention on Visual Fixation Skills of OMD Children}

The post-intervention comparison revealed significant difference in the level of Visual Fixation Skills between the experimental and control group, $\mathrm{F}(1,17)=37.08, p=0.001$. Partial eta squared $=0.686$ showed that effect size was large. There was significant improvement $(p<0.05)$ in the level of Visual Fixation Skills of group A $(M=0.39, S E=0.006)$ than group B $(M=0.44, S E=0.006)$ on the basis of treatment through training of Visual Fixation Exercises. The findings of Gaertner, Bucci, Ajrezo and Wiener-Vacher (2013) showed disagreement to this study which explained no any differences in the duration of the fixation between the experimental and control group on the basis of oculomotor training. Whereas Brodney et al. (2010) found significant improvement in fixation duration from 0.33 to 0.25 seconds per 100 fixations.

\section{Conclusions}

The study revealed significant improvement in the level of reading fluency of the Children with Oculomotor Dysfunction when provided the training of Eye Fixation Skills. Therefore, Null hypothesis $\mathrm{H}_{01}$ was rejected. The level of Eye Fixation Skills of the experimental group was significantly improved in terms of decreased duration of gaze fixation of Children with Oculomotor Dysfunction when provided the training through numerous Manual and Computer Animated Visual Fixation Exercises. Consequently, Null hypothesis $\mathrm{H}_{02}$ was also rejected. The study indicated that use of Eye Fixation Training is helpful in improving the reading abilities of the children with eye movement problems (oculomotor dysfunction). The study is very helpful for the School Education Authorities in addition to teachers for the development of rehabilitation plan involving gaze fixation exercises to remediate the reading fluency and fixation skills of Children with Oculomotor Dysfunction. 


\section{References}

Borsting, E., Rouse, M., Shin, S., \& McClallen, A. (2007). Repeatability of the Visagraph-II in the Analysis of Children's Eye Movements during Reading. Optometry \& Vision Development, 38(2), 67-73.

Brodney, A., Kehoe, P., \& Sinha, K.L.M. (2010). Vision Therapy Using Touch Screen Computers in an Elementary School. Journal of Behavioural Optometry, 21(2), 31-36.

Catts, H. W. \&Kamhi, A. G. (1999). The Language Basis of Reading: Implications of Classification and Treatment of Children with Reading Disabilities. Boston: Allyn \& Bacon.

Farrell, M. (2006). The Effective Teacher's Guide to Dyslexia and Other Specific Learning Difficulties. New York, NY: Rutledge.

Fischer, B. (2015). Saccade and Fixation Control. Retrieved from http://www.optomlab.com/saccade/

Gaertner, C., Bucci, M.P., Ajrezo, L., \& Wiener-Wacher, S. (2013). Binocular coordination of saccades during reading in children with clinically assessed poor vergence capabilities. Vision Search, 87, 2229. https://doi.org/10.1016/j.visres.2013.05.006

Guzman-Martinez, E. \&Leung, P. (2009). Rapid eye-fixation training without eye tracking. Psychonomic Bulletin and Review Journal, 16(3),491-496.

Hanna, D., \& Dempster, M. (2012). Psychology Statistics for Dummies. London: John Wiley \& Sons.

Hasbrouck, J., \&Tindel, G.A. (2006). Oral reading fluency: A valuable assessment tool for reading teachers. The Reading Teacher, 59(7), 636-644.

Heidi (2011). Visual Perception Skills Activities on 'Eye Can Learn'. Retrieved from http://www.pediastaff.com/blog/visual- perceptionskills activities on eye canlearn 4144

Johnson, R. (2016). Oculomotor Dysfunction. Retrieved from https://www.advancedvision therapycenter.com/about/blog/e_930/Signs ofaVisionProblem/2016/7/OculomotorDysfunction.htm 
Justice, L., Mashburn, A., \& Petscher, Y. (2013). Very Early Language Skills of Fifth-grade Poor Comprehenders. Journal of Research in Reading, 36(2), 172-185.

Knudson, D.V. \& Morrison, C.S. (2002). Qualitative Analysis of Human Movement. Aukland: Human Kinetics.

Koprinkova-Haristova, P., Mladinov, V., \&Kasabov, N.K. (2014). Artificial Neural Networks: Methods and Application in Bio/Neoroinformatics. New York: Springer Publications.

Labor, B. (2010). Saccade Control in Reading: Vision and Saccades. Retrieved from http://www. lookingforlearning.com/assess/sac.htm.

Lane, K.A. (2005). Developing Ocular Motor and Visual Perceptual Skills: An Activity Workbook. Thorofare: SLACK Incorporated.

Lederman, R. (2012). Lederman Vision. Retrieved from http://www.ledermanvision.com/english/ childrensvision.php.

Mangen, A. (2008). Hypertext fiction reading: haptics and immersion. Journal of Research in Reading, 31(4), 404-419.

Maples, W.C. (1995). NSUCO oculomotor test. Santa Ana, CA: Optometric Extension Program.

Martella, R.C., Nelson, J.R., Morgan, R.L., \& Marchand-Martella, N.E. (2013). Understanding and Interpreting Educational Research. New York, NY: The Guilford Press.

Oberlander, T. J., Olson, B. L., \& Weidauer, L. (2017). Test-retest reliability of the King-Devick test in an adolescent population. Journal of athletic training, 52(5), 439-445.

Okumura, T., Laukkanen, H., \& Tamai, H. (2008). Computerized Saccadic Eye Movement Therapy to Improve Oculomotor Control during Reading and Reading Rate in Adult Japanese Readers. Optometry of Vision Development, 39(4), 191-197.

Petrosyan, T. (2013). Focusing, eye teaming, and eye tracking dysfunctions. Retrieved from

http://eyecare.org/site/focusing-eye-teaming-and-eye-trackingdysfunctions/

Powers, M., Grisham, D., \& Riles, P. (2008). Saccadic tracking skills of poor readers in high school. Optometry, 79(5), 228-234. 
Robert, M. P., Ingster-Moati, I., Albuisson, E., Cabrol, D., Golse, B., \&Vaivre-Douret, L. (2014). Vertical and horizontal smooth pursuit eye movements in children with developmental coordination disorder. Developmental Medicine \& Child Neurology, 56(6), 595-600.

Rosengarth, K., Keck, I., Brandl-Ruhle, S., Frolo, J., Hufendiek, K., Greenlee, M.W., \& Plank, T. (2013). Functional and structural brain modifications induced by oculomotor training in patients with age-related macular degeneration. Journal of Front Psychology, 4,428.https://doi.org/10.3389/fpsyg.2013.00428.

Scheiman, M. \& Rouse, M.W. (2006). Optometric Management of Learning-related Vision Problems. St. Louse: Mosby Elsevier.

Sekznick, R. (2012). School Struggles: a guide to your shut down learner's success. New York: Sentient Publications.

Shaw-McMinn, L. (2014). Eye Movements in Children. Retrieved from http://suncityvision.com/eyemovements

Solan, H., Larson, S., Shelley-Tremblay, J., Ficarra, A., \& Silverman, M. (2001). Role of visual attention in cognitive control of oculomotor readiness in students with reading disabilities. Journal of Learning Disabilities, 34(2),107-118.

Special Education Resource Center (2013). Eye Can Learn. Retrieved from http://redbridgeserc.org/resources/entry/eye-can-learn/

Thiagarajan, P., Ciuffreda, K.J., Capo-Aponte, J.E., Ludlam, D.P \& Kapoor, N. (2014). Oculomotor neuro rehabilitation for reading in mild traumatic brain injury (mTBI): an integrative approach. Neuro Rehabilitation, 34(1), 129-146.

Tyagi, K. \& Misra, P. (2011). Basic Technical Communication. New Delhi: PHI Learning Private Limited.

Wethe, J., Leong, D., Pang, Y., \& Weil, R. (2015). Oculomotor training using King-Devick remediation and elementary school reading fluency outcomes. Vision Development and Rehabilitation, 1(2), 130-134.

\section{Citation of this Article:}

Nazir, M., \& Nabeel, T. (2019).Effect of training of eye fixation skills on the reading fluency of children with oculomotor dysfunction. Pakistan Journal of Education, 36(1), 61-80. 